\title{
Perception of soundscapes: An interdisciplinary approach
}

William J. Davies ${ }^{\mathrm{a}}$

Mags D. Adams ${ }^{\mathrm{a}}$

Neil. S. Bruce ${ }^{a}$

Rebecca Cain ${ }^{\mathrm{b}}$

Angus Carlyle

Peter Cusack ${ }^{\mathrm{c}}$

Deborah A. Hall ${ }^{\text {d, e }}$

Ken I. Hume ${ }^{f}$

Amy Irwin ${ }^{\mathrm{d}}$

Paul Jennings ${ }^{\mathrm{b}}$

Melissa Marselle $^{\mathrm{a}}$

Christopher J. Plack ${ }^{\mathrm{g}}$

John Poxon ${ }^{\mathrm{b}}$

a Acoustics Research Centre, Newton Building, University of Salford, Salford M5

4WT, UK, email: w.davies@ salford.ac.uk

${ }^{\mathrm{b}} \mathrm{WMG}$, University Of Warwick, Coventry CV4 7AL, UK

${ }^{c}$ London College of Communication, Elephant \& Castle, London SE1 6SB, UK

${ }^{\mathrm{d}}$ MRC Institute of Hearing Research, Nottingham NG7 2RD, UK

${ }^{\mathrm{e}}$ Division of Psychology, Nottingham Trent University, Burton Street, Nottingham, NG1 4BU, UK

${ }^{\mathrm{f}}$ Division of Health Science, Faculty of Science \& Engineering, Manchester Metropolitan University, Chester St, Manchester M1 5GD, UK

${ }^{\mathrm{g}}$ Human Communication and Deafness Division, University of Manchester, Manchester M13 9PL, UK

Corresponding author:

Dr William J. Davies

Acoustics Research Centre

Newton Building

University of Salford

Salford M5 4WT

UK

Tel: +44 (0)161295 5986

Fax: +44 (0)161295 5986

email:w.davies@salford.ac.uk 


\begin{abstract}
This paper takes an overall view of findings from the Positive Soundscape Project, a large inter-disciplinary soundscapes study. Qualitative fieldwork (soundwalks and focus groups) have found that soundscape perception is influenced by cognitive effects such as the meaning of a soundscape and its components, and how information is conveyed by a soundscape, for example on the behaviour of people within the soundscape. Three significant clusters were found in the language people use to describe soundscapes: sound sources, sound descriptors and soundscape descriptors. Results from listening tests and soundwalks have been integrated to show that the two principal dimensions of soundscape emotional response seem to be calmness and vibrancy. Further, vibrancy seems to have two aspects: organisation of sounds and changes over time. The possible application of the results to soundscape assessment and design are briefly discussed.
\end{abstract}

Keywords: soundscape, soundwalk, emotion, perception, noise 


\section{Introduction}

The concept of the soundscape is a broad one, accommodating the complete sound environment in a location and the human response to it. For acousticians, one key attraction of the soundscape concept is that it seems to be a better fit than noise level to the many factors influencing human experience in the outdoor environment. The disadvantage of this is that it is difficult to characterise these many factors and to explain how they interact with each other and how they affect human experience and behaviour. Good progress has however been made in important areas such as theoretical models of soundscape perception, understanding cognitive categories of sounds and soundscapes and in establishing the important subjective dimensions of some aspects of soundscape perception. These areas are briefly discussed below.

A small number of theoretical models exist to aid understanding of soundscape perception. These generally break down the problem into a number of elements considered important and are a way of starting to think about a perception problem with a large number of potential factors. The model proposed by Job et al. [1] is based on the top-level components of soundscape (all sounds), 'enviroscape' (other environmental factors) and 'psychscape' (listener variables). Zhang and Kang's model [2] is similar but perhaps more detailed. It has four top-level elements: source, space, people and environment. Each element has several variables attached, both physical/quantitative and perceptual/qualitative. Schulte-Fortkamp and Fiebig [3] attempted to model the process of a person perceiving and responding to a soundscape. They described five elements or processes which can all occur in parallel: the acoustics of the sound(scape), the initial perception, a negotiation process internal to the listener, psychological reactions and behavioural response. There is 
more than one possible model partly because there are still few data characterising the many variables involved and how they interact.

One important variable in soundscape perception is simply how people think about different sounds. A fundamental aspect of this is the way a listener categorises sounds. A range of approaches have been used to establish classifications and categorisations of both sounds and soundscapes. For example, Maffiolo et al [4] asked listeners to sort urban soundscapes (based on loudness or pleasantness) and found two generic categorisation types; 'event sequences', where individual sounds can be distinguished within the soundscape and 'amorphous sequences', whereby sounds are not easily distinguishable. Other research, for example Kuwano et al [5], has shown that a soundscape is often perceived as a collection of the individual sounds of which it is comprised; soundscape assessment is therefore influenced by the assessment of those sound types. This implies that soundscape assessment relies upon the identification of the sounds, the prominence of the sounds, and potentially the ratio of certain sound types to other sound types within the soundscape. Perhaps the most common category set that emerges from this type of research is one where listeners have classified sounds into the types 'natural', 'human' and 'mechanical' [6]. Another important finding from this area of work, however, is that the category set used by listeners is contingent - it depends on several variables, especially location and soundscape.

Besides asking how listeners break sounds and soundscapes down into categories, one can also ask how many psychological dimensions the listener response has. The successful precursor here is in auditorium acoustics, where the sound of a concert hall has been shown to have four subjective dimensions: loudness, reverberance, clarity and spaciousness [7]. Decomposing soundscape perception in a 
similar way is more difficult because there are many more variables (what sort of soundscape? What aspect of perception?) and because some of the important cognitive processes (e.g. categorisation) are less amenable to dimensional analysis. Kang [8] used 18 semantic differential scales with 223 subjects in two urban squares. He extracted four principal factors. All the factors have significant relationships with many of the 18 scales, so attempting to summarise the factors in one word leads to some generalisation. Nevertheless, Kang's perceptual factors can be described as: relaxation, communication, spatiality and dynamics. Guillén and López Barrio [9] conducted a similar investigation using the same method and found three dimensions which explained $66 \%$ of the variance in sound quality judgements. They named the dimensions, emotional evaluation and strength (42\%), activity (14\%), and clarity (10\%). Axelsson et al. have also used a principal component analysis (PCA) to characterise the response of 100 listeners to 50 soundscapes on 116 semantic scales [10]. They produced a three-dimensional space with factors pleasantness, eventfulness and familiarity explaining $50 \%, 18 \%$ and $6 \%$ of the variance respectively.

These studies raise many interesting questions on how to relate the perceptual dimensions with qualitative categorisation work on the one hand, and how to translate quite broad dimension names into quantitative measurements and hence to the acoustic sound field, on the other hand. Even if this can be done, there still remains a significant gap in connecting scientific studies of the soundscape to the adventurous explorations of sound artists. Before acousticians became interested in soundscapes, sound artists were at work recording, composing and intervening in soundscapes. Less constrained than science, sound art can often provoke listeners to become more aware of their soundscape [11], or provide insights into what is significant to listeners [12], or suggest ways of intervening in a soundscape to improve it (or at least change it) 
[13]. To date there have been relatively few collaborations between soundscape art and soundscape science, though the work of Hiramatsu and Torigoe [14] is a notable exception.

It is notable that the definition of the term soundscape is itself not yet standardised; for the purposes of this project, we used the working definition "the totality of all sounds within a location with an emphasis on the relationship between individual's or society's perception of, understanding of and interaction with the sonic environment." This is based on the definition by the World Soundscape Project [15]. The efforts of ISO WG54 to arrive at a standardised definition are acknowledged [16].

Different disciplines have tended to focus on subsets of the soundscape problem and, though there is a wide agreement that a holistic perspective is desirable, most soundscape projects are grounded in a single discipline. The Positive Soundscape Project (PSP) set out from the start to be interdisciplinary - that is, to synthesise a shared perspective on soundscapes from a range of disciplines. This paper has two aims: to report the qualitative experiments of PSP in detail, and to show how these qualitative results integrate with quantitative PSP experiments reported in other papers, to form a broad inter-disciplinary view of soundscapes.

\section{Overview of the whole project.}

The disciplines involved in PSP were acoustics, manufacturing, sound art, social science, psychoacoustics, physiology, and neuroscience. The project objectives that are relevant to the work discussed in this paper were:

- To determine what individuals/groups perceive to be component parts of a soundscape. 
- To determine how individuals value these components.

- To classify types of soundscape.

- To bring together artistic, social, psychological and physical science and manufacturing approaches.

Following an initial pilot test [17] the project team decided to use multiple methods to intensively study a small number of places. The main methods used were chosen because they each seemed capable of capturing key elements of listener experience from the viewpoint of the different disciplines involved. The parts of the project, their methods and the main results are outlined in Table 1. The project work can be roughly grouped into three types: quantitative, qualitative and artistic. This paper concentrates on the main qualitative work: the soundwalks, interviews and focus groups. Table 1 shows that there were many links between the different parts of the project, but the heart of it was that soundwalks were conducted in Manchester and London and recordings of the soundscapes encountered were made and used throughout the project. More information on the other project parts can be found in the references in Table 1 .

$<<$ Table 1 about here $>>$ 


\section{Method}

Early on, the team chose to focus on external urban soundscapes, partly because these represented potential for variety, conflict and the need for design. The field work centred on two sound walk routes, one in Manchester and one in London. The Manchester route is shown in Fig. 1. The sound walk method used differed from the traditional method originally used by Schafer [31]. Schafer's method is often still used today and typically involves a group of people being led around an area or along a route. Silence is maintained for the duration - which may be as long as an hour and impressions of the entire soundscape discussed only at the end. As well as overall impression, we were also interested in how perceptions of the soundscape changed as participants moved from one place to another. We were concerned that acoustic memory would not allow a detailed exploration of this after a complete soundwalk, so we devised a method which linked a series of key soundscapes [32]. Participants (usually just one participant with the researcher) walked in silence between the key locations. The Manchester route travelled from a pedestrianised shopping street (Market Street), through an indoor shopping mall (Arndale Centre), to a pedestrianised square (St Ann's Square), along a main road with high traffic levels and shops, to a small park shielded from traffic (St John's Gardens). In each key space, a short interview took place based on the questions shown in Table 2. Binaural recordings were made of the soundscapes along the soundwalk route for laboratory listening tests $[18,19$, this issue]. Ambisonic and close-miked mono recordings were also made of the soundscapes for the soundscape sequencer [23, 24]. 
$<<$ Fig. 1 about here $>>$

$<<$ Table 2 about here $>>$

As well as the soundwalks, four focus groups were conducted. A focus group is simply a discussion on a specific issue facilitated by a researcher. Naturalistic discussion allows ideas to emerge and be tested by the group, so that the researcher can potentially capture detailed and relatively unbiased opinions. This method is well suited to explore how people consider and understand sound in the urban environment and the meanings that they attribute to it. Although the pioneering work of Dubois et al. [33] has shed some light on how soundscapes generate meaning and how this influences behaviour, it seems fair to say that it is still largely unclear how people process and create meaning from different types of sound in different situations, contexts and times - and how they evaluate whether sounds are wanted or unwanted. Added to this is how they evaluate the complex 'sum of sounds' in any urban space the soundscape - and what they value and appreciate. Thus, the main problems that the focus groups addressed are how people understand 'soundscapes', how they might distinguish a positive soundscape from a negative one, and what other issues have an impact on people's evaluation of soundscapes. Of course, it is likely that the answers are different depending on who is answering, so the four focus groups used different participants:

- Adults aged 18-25,

- Adults aged 60 or older,

- Hard of hearing adults with moderate to severe hearing loss who use assistive listening devices (e.g. hearing aids or cochlear implants) and 
- Experts (professionals from urban design and development or acoustics).

An example of the prompt questions used in the focus groups is given in Table 3.

<< Table 3 about here >

\section{Outcomes}

\subsection{The listener in the soundscape}

Audio recordings of the focus groups were transcribed and the text of these transcripts was analysed qualitatively, using grounded theory [34]. This analysis is an inductive and iterative approach that involved the investigators subjectively applying codes to sections of the text on repeated readings to progressively build up a picture of the main themes and ideas in the discussion. Three key questions for the analysis were:

- How is a soundscape evaluated as positive or negative?

- How does a soundscape affect behaviour and psychological response?

- What is a positive soundscape?

Four factors emerged as important in evaluating a soundscape as positive or negative: behaviour, attention, information and individual differences. In most cases, there was no strong difference between the four different focus groups. Each factor is briefly discussed below; the order does not imply a rank order. The first factor relates to human behaviour and activity. Participants evaluated a soundscape according to whether they perceived they had any control over their soundscape environment and whether the sound generated in the soundscape met their expectations of norms (including both norms of social behaviour and place norms). Soundscapes that are compatible for one's own purposes and support one's own behaviours are also 
evaluated as positive. Attention is the second factor in soundscape evaluation. Participants tended to categorise sounds into foreground and background. According to participants, soundscapes could be evaluated as negative if foreground sounds required more attention allocation, by being loud, unpredictable or persistent. On the other hand, sounds that "blend together" were harmonious or positive. The third factor in soundscape evaluation related to information processing. A soundscape providing information to the listener was considered positive. If a soundscape stimulates us to explore and comprehend the environment, this too is evaluated as positive. However, the information must be correct or expected: participants said the sound and its source should be congruent and spoke of "schizophonic" soundscape experiences as negative. The fourth and final factor that emerged is that of individual difference between listeners. Participants spoke of individual preference in soundscapes and discussed how associations from memory can influence soundscape evaluation. Emotionally charged associations were thought to be particularly influential. The group of older participants also said that a memory of a past soundscape could be significant in evaluating a current one.

The second key area analysed was how the soundscape affects behaviour and psychological response. Here, three factors were significant: psychological reactance, awareness of one's own sound-making and mood. Psychological reactance is a term denoting how a perceived loss of control over the soundscape results in an individual's attempt to regain control. Here participants' discussion covered two strategies, behavioural and cognitive control. Behavioural control occurs when we engage in a behavioural response to avoid an unwanted sound(scape) or try to modify an unwanted sound. There were some differences between older and younger participants. Younger participants discussed leaving an unwanted soundscape or 
wearing headphones. However, the older focus group discussed learned helplessness; after repeated attempts to control unwanted sounds but to no avail, they have ceased trying to change the situation. Cognitive control means a reappraisal of a sound(scape), including tolerance of an unwanted sound. The younger focus group discussed simply being aware of the limitations of our control over the soundscape and accepting the situation. This might be termed secondary control - reappraisal of the soundscape and becoming satisfied with it. Control strategies are related to habituation, in that we will not try to control soundscapes that we have become adapted to. Participants thought that habituation to commonly heard sounds explained some differences in response between different individuals. The most common examples cited were road and air transport.

The second factor emerging from discussion of behaviour and response was that of self-awareness of one's own sound generation. The ways in which we generate sound (walking, talking, etc), the extent to which we are aware of it and how we feel about it are all influenced by the soundscape. Participants spoke of how this relates to perceived social and place norms of the appropriate behaviour and acceptable sound level of a place, and also how it relates to an individual's own personal beliefs about social norms. (It is perhaps interesting that the younger and older focus groups both thought this important.) The final key factor in the discussions on behaviour was mood. Participants agreed that there is a transactional relationship between the soundscape and one's emotional state. Indeed, when the soundscape seems in harmony with our feelings then we regard it as positive.

The third and last key question for analysis concerned what makes a positive soundscape. Here the focus groups identified three major constituents. Firstly, they thought that a positive soundscape would include natural sounds. Secondly, they 
identified that the hubbub from human voices and human presence creates vibrancy, which was perceived as positive. Finally, participants said that positive soundscapes engender positive emotional states, such as happiness (from happy human sounds or natural sounds such as a stream, for example) and relaxation (from natural sources, human speech, or even the comfort provided by background traffic).

It is striking that the four factors in evaluating a soundscape as positive or negative have little relationship to acoustic variables. Some of the percepts discussed under the factor attention - loud, persistent - may well correlate to objective acoustic metrics, and the recent work in modelling attention in soundscapes [35] is given added weight by the present findings. But the four factors seem to consist largely of higher-level cognitive processes, particularly related to meanings of various kinds. There is the meaning of other peoples' behaviour, the meaning of information and expectation, and the meanings drawn from memory or emotional association. The discussions focusing on behaviour and response are also concerned more with cognition than perception or acoustics. A major influence on behaviour seems to be the extent to which people feel a sense of control over their exposure to a soundscape. It seems more likely that soundscape designers will produce a positive soundscape if people can control their exposure to it. The way in which a soundscape influences mood and emotional states such as happiness is seen to affect both our behaviour in a place and our rating of the soundscape as positive. The constituent sounds of a soundscape are also important factors in whether it is categorised as positive. As other researchers have found $[33,36,37]$ the two categories of natural sounds and human sounds are important positive indicators. Indeed, our own data are consistent with this claim since mechanical sounds tended to rank low on pleasantness [19]. One could hypothesise that this is again because of meaning: natural sounds have associations 
with tranquility [38] and relaxation, while human sounds convey a sense of social connection.

The apparent dominance of higher-level cognitive factors such as the meaning of a soundscape and the emotion it inspires clearly presents a considerable challenge for the acoustic designer. It is unlikely that meaning can be correlated with simple acoustic or psychoacoustic metrics, for example. However, by comparison with the design of the visual environment, we see that it may be sensible to allocate some important aspects of soundscape design to the aesthetic realm, where an architect or designer makes artistic choices. This would include the meaning of the soundscape, the extent to which it fits the intention or meaning of the place. A good example of this is Sheaf Square in Sheffield, where the water feature makes audible reference to the adjacent train station by imitating the rhythms of a train running on rails [6]. However, it is equally important to explore other aspects of user experience reported above. Characterising the cognitive and emotional response is addressed in section 4.3 below. Before that, we examine the perception of the structure of soundscapes in more detail.

\subsection{Components of a soundscape}

The focus groups provide information on quite broad questions about how people think of the concept of a positive soundscape and how soundscapes affect behavioural response. In contrast, the soundwalk interviews allowed us to look at how participants thought about their direct experience of some specific urban soundscapes. The transcripts of the soundwalk interviews were analysed in a similar way to those of the focus groups. What emerged was a map of the language people use when talking about sounds and soundscapes. It was found that the terms used could be grouped into 
three concepts: sound sources, sound descriptors and soundscape descriptors. Sound sources are terms referring to physical entities - these might be complex multiple objects (e.g. traffic) or components (e.g. brakes). Sound descriptors are descriptions of sounds - these might be nouns (rattle), adjectives (whirring) or phrases (delicate sounds). Soundscape descriptors deal with the totality of what is heard. The relationship between these is conceptualised in Fig. 2 .

$<$ Fig. 2 about here >>

Soundscape descriptors clustered under four categories which we have named cacophony, hubbub, constant and temporal. In the category cacophony are terms used such as cacophony, symphony of racket, jumble of sound, kind of mud, morass and mishmash of sound. The category refers to a soundscape that is perceived as a negative mix of sounds and is associated with a negative listening experience. The category hubbub includes terms like hubbub, symphony of sound, sound soup and tapestry of sound. It refers to a soundscape that is perceived as a positive mix of sounds and is associated with a positive listening experience. In the category constant, listeners are referring to the constant sound of the soundscape, a monotonous, unchanging soundscape or a soundscape where something (one particular sound) masks everything else. This category often refers to a soundscape perceived to be a negative listening experience but there are instances where it is used to describe a positive experience. In the category temporal, listeners are referring to dynamic changes in the soundscape and describe sounds as ticking over, coming in waves, like the sea or stopping and starting. In general, they describe changes on the order of seconds to minutes; a change that can be heard within one listening experience. 
The four soundscape categories seem to be related on two axes. The categories can be used as semantic labels at opposite ends of each axis. Thus, the cacophony hubbub axis relates to the numbers of different sounds making up the soundscape and the levels of dissonance or discord perceived by the listener within the mix. It incorporates an element of pleasantness or approval of the soundscape by the listener. The constant - temporal axis relates to the amount and frequency of change within the soundscape, the rhythm and level of monotony of the soundscape. It contains little element of pleasantness or judgement by the listener about their preference. In themselves, these axes are not a complete characterisation of soundscape perception, just as the focus group themes are not. But they do seem to indicate that the way sounds combine to make up a soundscape is important and that this interplay between sounds and soundscape might be characterised on two axes which describe how sounds are organised and how they change over time. These findings seem to reinforce the widespread artistic conceptualisation of the environmental soundscape as being a sort of musical composition [31].

However only the outer ring in Fig. 2 is concerned with these soundscape axes. The number of terms in the diagram reflects the fact that participants used more terms for sound sources and sound descriptors. The focus on physical sound sources and events is strong. Participants seem to want to identify sound sources and where they cannot, then quite evocative description ("a fluttering noise") can be used to better specify the sound. During the process of analysis, there was some evidence of a difficulty, a lack, in the language that participants used to describe sound and especially soundscapes. This lack of language may relate to a lack of an aesthetic of sound and perhaps reflects the dominance of the visual in the design and conceptualisation of the environment. Just as in the focus groups, however, cognitive 
effects are strongly represented as participants identify sounds with sources or events to give them meaning. The relationship between the meaning of the sounds and the meaning of the soundscapes is not yet completely clear. Fig. 2 suggests that a part of the relationship is the auditive figure-ground phenomenon [39]: identifiable sound sources are in the (attention) foreground and soundscape descriptors are the background. There is clearly material for further research here to clarify the relationships between source and soundscape, foreground and background, and perceived space and auditory attention. In contrast to this emerging complexity, some researchers have sometimes used the lack of clarity on the relationship between sources and soundscapes to suggest that the concept of a soundscape is invalid. Sometimes it is argued that a soundscape is no more than a collection of individual sounds or that a soundscape is just the aural perception of physical events (happening in some specific place) [40]. It is clear that both ideas play a significant part in the (perceived) soundscape - one could think of the list of sounds and the list of events in a place as being two different projections of the soundscape. Both lists can be derived from the soundscape but neither (nor both together) is a complete characterisation of a soundscape.

\subsection{Dimensions of a soundscape}

The soundwalk interviews allowed a focus on how people talk about sounds and soundscapes and provided a view of the cognitive components of a (perceived) soundscape. This qualitative research provides tentative evidence that a soundscape is thought about on two axes: constant-temporal and cacophony-hubbub. The laboratory listening tests in PSP also found two dimensions, though they are not identical to the qualitative axes. Laboratory experiments by Cain et al. [18, this issue] presented 
soundscapes at their recorded level and asked participants to focus on how the soundscape made them feel and then evaluate their experience on five semantic differential scales. These experiments found that almost $80 \%$ of the variance could be explained by two principal components. For short, these components are called calmness and vibrancy. The calmness component is a combination of the semantic differential scales of calmness, comfort and intrusiveness. The vibrancy component is the semantic differential scale of vibrancy. These would seem to agree reasonably well with Kang's first two components, relaxation and dynamics [8] and also with the dimensions of pleasantness and eventfulness found by Axelsson et al. [10].

Another set of laboratory listening experiments was conducted as part of PSP by Hall et al. [19, this issue]. Using the larger set of recordings, principal component analysis produced broadly similar results, with two components explaining $71 \%$ of the total variance in the subjective responses. This time, pleasantness was included on a rating scale and it was found to load heavily onto the principal component calmness, along with the scales of calmness, comfort and intrusiveness

How do the qualitative axes relate to these principal components? First, it should be noted that they describe subtly different aspects of the listener experience. In the laboratory, subjects rated how the soundscape made them feel. On the soundwalk, participants were describing the soundscape, not their feelings. These are the two essential features of the usual definition of the soundscape: the sound environment in a place (our qualitative axes) and the listener response to it (our quantitative principal components). Given that distinction, there does seem a strong relation. The qualitative axes, cacophony-hubbub and constant-temporal may describe the two ways in which a soundscape can produce an emotional response of vibrancy in the listener. The first component, calmness is perhaps more purely an emotional response and is strongly 
related to overall pleasantness. Thus it is suggested here that the perception of the soundscape can be characterised by calmness and vibrancy, and vibrancy splits into two components, cacophony-hubbub and constant-temporal. This suggests a strong role for the sound artist or designer in helping to compose the elements of the soundscape: the artistic task would be to design (compose) a suitable level of vibrancy by attempting to manipulate the mixture of sound sources and how they change over time. The parallel with musical composition is clear and we are reminded that many sound artists compose pieces of recorded 'soundscape' music as well as intervening in the soundscape of the built environment.

\subsection{Applications to soundscape design}

Having identified both perceptual dimensions and cognitive components of urban soundscapes, it is natural to ask how this information could be applied to assess existing soundscapes or design new ones. One route is to try to develop signal processing metrics: the acoustic environment is at least partly responsible for the soundscape perception so perhaps one can analyse the recorded soundscape in some way to predict the perceived response. However, results thus far are not encouraging: ratings of pleasantness and vibrancy for the PSP soundscape samples were not predicted well by any of the usual psychoacoustic variables, such as loudness, roughness, fluctuation strength and sharpness, or variables based on averaged spectral shape [19, this issue]. Alternatively, existing soundscapes can be evaluated using a questionnaire in the field with rating scales for the main perceptual dimensions supplemented by questions trying to elicit dominant sources or cognitive components [29]. The failure of physical metrics which process the soundscape as a whole is not too surprising (in hindsight, at least!) when we remember that the focus groups and 
soundwalk interviews found significant roles for high-level cognition such as the meaning and source identification and categorisation. In the future, it may be possible to predict some aspects of soundscape perception with signal metrics, but these may have to be supplemented with source and soundscape-type identification algorithms.

Several of the experiments within PSP used simulated soundscapes, with a particular emphasis on finding a way for people to engage with and manipulate a realistic soundscape. This work indicated that it is possible to achieve a kind of ecological validity: participants make the same qualitative response to the simulator as they do to the real soundscape [23]. The typical experience was of an ambisonic reproduction of an ambient soundscape track with several specific and variable sources overlaid. People tended to identify and categorise sounds and sources and to rate sources and soundscapes for pleasantness in the same way as they do for real soundscapes. They also report feeling very engaged by the task of manipulating a simulated soundscape. Our current simulations are crude compared to, say, the state of the art in concert hall auralisation. Nevertheless, it seems reasonable to anticipate that we will eventually develop simulations realistic enough to be used reliably for built environment design. A key challenge in the future will be to build a simulator that produces the desired cognitive responses as well as simply the expected low-level perceptions.

\section{Conclusions}

The Positive Soundscape Project has synthesised the methods and results from several different disciplines to provide a coherent characterisation of listener response to an urban soundscape. High-level cognitive effects have been shown to be at least as significant as low-level percepts or physical acoustic attributes. People seem to extract 
meaning from the soundscape in terms of human activity and behaviour, and in information conveyed by the soundscape. Individual differences can of course be significant in producing meaning. People are aware of their attention being driven to some extent by the structure of the soundscape. This structure can be conceived of as three main components: sound sources, sound descriptors and soundscape descriptors. The soundscape concept allows us to see that the distinction between sound and noise is essentially an emotional one. Results from listening tests and soundwalks have been integrated to show that the two principal dimensions of this emotional response seem to be calmness and vibrancy. Further, vibrancy seems to have two aspects: organisation of sounds (cacophony - hubbub) and changes over time (constant temporal). Physiological experiments have demonstrated that the body and brain respond to emotional content as well as simply noise level. The value of this interdisciplinary work is shown in the way that the findings of listening tests, qualitative fieldwork, artistic practice and physiological experiments largely agree, giving confidence in the results of each.

\section{Acknowledgments}

The Positive Soundscape Project was wholly funded by the UK Engineering and Physical Sciences Research Council, under grant number EP/E011624/1. 


\section{REFERENCES}

[1] R.F.S. Job, J. Hatfield, N.L. Carter, P. Peploe, R. Taylor, S. Morrell, Reaction to noise: the roles of soundscape, enviroscape and psychscape, in: Inter-Noise 1999, Fort Lauderdale, Florida, USA, 1999.

[2] M. Zhang, J. Kang, Towards the evaluation, description, and creation of soundscapes in urban open spaces, Environment and Planning B: Planning and Design 34(1) (2007) 68-86.

[3] B. Schulte-Fortkamp, A. Fiebig, Soundscape analysis in a residential area: An evaluation of noise and people's mind, Acta Acustica united with Acustica 92(6) (2006) 875-880.

[4] A.V. Maffiolo, M. Castellengo, D. Dubois, Qualitative judgements of urban soundscapes., in: Inter-Noise 99, Fort Lauderdale, Florida, USA, 1999.

[5] S. Kuwano, N. S., T. Kato, J. Hellbrueck, Memory of the loudness of sounds and its relation to overall impression., in: Forum Acusticum, Seville, Spain, 2002.

[6] S.R. Payne, W.J. Davies, M.D. Adams, Research into the Practical and Policy Applications of Soundscape Concepts and Techniques in Urban Areas. 2009, Department for Environment, Food and Rural Affairs: London.

[7] Y. Ando, Calculation of subjective preference at each seat in a concert hall, J. Acoust. Soc. Am. 74 (1983) 873-887.

[8] J. Kang, Urban Sound Environment. London: Taylor and Francis. 2007.

[9] J.D. Guillen, I. Lopez-Barrio, The soundscape experience, in: 19th International Congress on Acoustics, Madrid, 2007.

[10] O. Axelsson, M.E. Nilsson, B. Berglund, A principal components model of soundscape perception, Journal of the Acoustical Society of America 128(5) (2010) 2836-2846. 
[11] H. Westerkamp, Soundwalking, Sound Heritage 3(4) (1974) 18-27.

[12] H. Järviluoma, A. Koivumäki, M. Kytö, H. Uimonen, In search of mutifaceted Finnish soundscapes, in: A. Carlyle, (Ed.),Autumn Leaves: Sound and the Environment in Artistic Practice, Double Entendre, Paris, 2007 pp. 89-93.

[13] S. Jouan, Auralization of urban soundscaping designs using the Arup SoundLab, Journal of the Acoustical Society of America 123(5) (2008) 3861.

[14] K. Hiramatsu, A review of soundscape studies in Japan, Acta Acustica United with Acustica 92(6) (2006) 857-864.

[15] B. Truax, Acoustic Communication, 2nd ed., Santa Barbara, CA, USA: Greenwood Publishing Group. 2000.

[16] A.L. Brown, J.A. Kang, T. Gjestland, Towards standardization in soundscape preference assessment, Applied Acoustics 72(6) (2011) 387-392.

[17] W.J. Davies, M.D. Adams, N.S. Bruce, R. Cain, A. Carlyle, P. Cusack, K.I. Hume, P. Jennings, C.J. Plack, The Positive Soundscape Project, in: 19th International Congress on Acoustics, Madrid, 2007.

[18] R. Cain, P. Jennings, J. Poxon, The development and application of the emotional dimensions of a soundscape, Applied Acoustics this issue (2012)

[19] D.A. Hall, A. Irwin, M. Edmondson-Jones, S. Phillips, J.E.W. Poxon, An exploratory evaluation of perceptual, psychoacoustic and acoustical properties of urban soundscapes, Applied Acoustics this issue (2012)

[20] A.L. Irwin, D.A. Hall, A. Peters, C.J. Plack, Listening to urban soundscapes: Physiological validity of perceptual dimensions, Psychophysiology 48 (2011) 258-268.

[21] K. Hume, M. Ahtamad, Physiological responses to and subjective estimates of soundscape elements, Applied Acoustics this issue (2012) 
[22] W.J. Davies, P.Z. Mahnken, P. Gamble, C. Plack, Measuring and mapping soundscape speech intelligibility, in: Euronoise 2009, Edinburgh, U.K., 2009.

[23] N.S. Bruce, W.J. Davies, M.D. Adams, Development of a soundscape simulator tool, in: Internoise 2009, Ottawa, Canada, 2009.

[24] P. Cusack. The Sound Database. Last accessed 9 July 2010; Available from: http://www.petercusack.org/index.php.

[25] P. Cusack. Favourite London Sounds. Last accessed 9 July 2010; Available from: http://www.favouritelondonsounds.org/.

[26] P. Cusack, S. Elvins, Fédération Internationale des Chasseurs de Sons, N.

Gansterer, S. Gill, D. Holdsworth, J. Kirkegaard, C. Norment, D. Scarfe, Thomson, Craighead, Sound Escapes, Space Gallery, 129 - 131 Mare Street, London, UK. Curators A. Carlyle and I. Revell (25 July - 15 August 2009).

[27] P. Jennings, R. Cain, A framework for improving urban soundscapes, Applied Acoustics this issue (2012)

[28] M. Adams, B. Davies, N. Bruce, Soundscapes: an urban planning process map, in: Internoise 2009, Ottawa, Canada, 2009.

[29] W.J. Davies, M.D. Adams, N.S. Bruce, R. Cain, P. Jennings, A. Carlyle, P. Cusack, K. Hume, C. Plack, A positive soundscape evaluation system, in: Euronoise 2009, Edinburgh, U.K., 2009.

[30] N.S. Bruce, W. Davies, M.D. Adams, Expectation as a factor in the perception of soundscapes, in: Euronoise 2009, Edinburgh, U.K., 2009.

[31] R.M. Schafer, The tuning of the world. New York: Knopf. 1977.

[32] M. Adams, N. Bruce, W. Davies, R. Cain, P. Jennings, A. Carlyle, P. Cusack, K. Hume, C. Plack, Soundwalking as a methodology for understanding soundscapes, in Proc. I. o. A., Reading, U.K., 2008. 
[33] D. Dubois, C. Guastavino, M. Raimbault, A cognitive approach to urban soundscapes: Using verbal data to access everyday life auditory categories, Acta Acustica United with Acustica 92(6) (2006) 865-874.

[34] A.C. Strauss, J. Corbin, Basics of Qualitative Research: Grounded Theory Procedures and Techniques, 2nd ed., Newbury Park, California: Sage Publications. 1990.

[35] D. Botteldooren, B. De Coensel, A model for long-term environmental sound detection, in,2008 Ieee International Joint Conference on Neural Networks, Vols 1-8, Ieee, New York, 2008 pp. 2017-2023.

[36] W. Yang, J. Kang, Soundscape and sound preferences in urban squares: A case study in Sheffield, Journal of Urban Design 10(1) (2005) 61-80.

[37] M.E. Nilsson, B. Berglund, Assessment of outdoor soundscapes in quiet areas, J. Acoust. Soc. Am. 117(4) (2005) 2592-2592.

[38] R. Pheasant, K. Horoshenkov, G. Watts, B. Barrett, The acoustic and visual factors influencing the construction of tranquil space in urban and rural environments tranquil spaces-quiet places?, Journal of the Acoustical Society of America 123(3) (2008) 1446-1457.

[39] A.S. Bregman, Auditory scene analysis: the perceptual organization of sound. MIT Press. 1994.

[40] T. Ingold, Against soundscape, in: A. Carlyle, (Ed.),Autumn Leaves: Sound and the Environment in Artistic Practice, Double Entendre, Paris, France, 2007 pp. 
Table 1. The parts of the Positive Soundscape Project.

\begin{tabular}{|c|c|c|c|c|c|c|}
\hline & Part & Method & Main output & Reference & $\begin{array}{l}\text { Inputs } \\
\text { from }\end{array}$ & $\begin{array}{l}\text { Outputs } \\
\text { to }\end{array}$ \\
\hline$a$ & $\begin{array}{l}\text { Soundwalks } \\
\text { and } \\
\text { interviews }\end{array}$ & $\begin{array}{l}\text { Qualitative: } \\
\text { semi- } \\
\text { structured } \\
\text { interviews }\end{array}$ & $\begin{array}{l}\text { Cognitive } \\
\text { soundscape } \\
\text { components }\end{array}$ & This paper & $\mathrm{c}, \mathrm{h}$ & $\begin{array}{l}\mathrm{b}, \mathrm{c}, \mathrm{f}, \\
\mathrm{g}, \mathrm{h}, \mathrm{i}, \\
\mathrm{j}, \mathrm{k}, \mathrm{l}\end{array}$ \\
\hline $\mathrm{b}$ & Focus groups & Qualitative & $\begin{array}{l}\text { Cognitive } \\
\text { soundscape } \\
\text { features }\end{array}$ & This paper & $\mathrm{a}, \mathrm{h}$ & $\begin{array}{l}\mathrm{f}, \mathrm{h}, \mathrm{i}, \mathrm{j}, \\
\mathrm{k}, \mathrm{l}\end{array}$ \\
\hline $\mathrm{c}$ & $\begin{array}{l}\text { Listening } \\
\text { tests }\end{array}$ & $\begin{array}{l}\text { Quantitative: } \\
\text { semantic } \\
\text { differential } \\
\text { scales }\end{array}$ & $\begin{array}{l}\text { Perceptual } \\
\text { dimensions: } \\
\text { calmness and } \\
\text { vibrancy }\end{array}$ & $\begin{array}{l}{[18, \text { this }} \\
\text { issue }] \&[19, \\
\text { this issue }]\end{array}$ & $\mathrm{a}, \mathrm{h}$ & $\begin{array}{l}\mathrm{d}, \mathrm{e}, \mathrm{i}, \\
\mathrm{j}, \mathrm{k}\end{array}$ \\
\hline $\mathrm{d}$ & Neuroscience & $\begin{array}{l}\text { Quantitative: } \\
\text { fMRI scans }\end{array}$ & $\begin{array}{l}\text { Validation of } \\
\text { perceptual } \\
\text { dimensions; } \\
\text { brain images }\end{array}$ & [20] & $\mathrm{c}$ & $\mathrm{i}, \mathrm{j}, \mathrm{k}$ \\
\hline $\mathrm{e}$ & Physiological & $\begin{array}{l}\text { Quantitative: } \\
\text { heart rate, } \\
\text { galvanic skin } \\
\text { response }\end{array}$ & $\begin{array}{l}\text { Relationship of } \\
\text { basic } \\
\text { physiology to } \\
\text { perception }\end{array}$ & $\begin{array}{l}{[21, \text { this }} \\
\text { issue }]\end{array}$ & $\mathrm{c}$ & $\mathrm{i}, \mathrm{j}$ \\
\hline $\mathrm{f}$ & Speech & Quantitative: & Draft & {$[22]$} & $\mathrm{a}, \mathrm{b}$, & $\mathrm{i}, \mathrm{j}$ \\
\hline
\end{tabular}




\begin{tabular}{|c|c|c|c|c|c|c|}
\hline & intelligibility & $\begin{array}{l}\text { signal } \\
\text { processing } \\
\text { and listening } \\
\text { tests }\end{array}$ & $\begin{array}{l}\text { modification to } \\
\text { speech } \\
\text { intelligibility } \\
\text { index }\end{array}$ & & & \\
\hline $\mathrm{g}$ & $\begin{array}{l}\text { Soundscape } \\
\text { simulator }\end{array}$ & $\begin{array}{l}\text { Artistic and } \\
\text { quantitative }\end{array}$ & $\begin{array}{l}\text { Simulation } \\
\text { device/method } \\
\text { and webpage }\end{array}$ & {$[23] \&[24]$} & $a, j$ & $\mathrm{~b}, \mathrm{i}, \mathrm{j}, \mathrm{l}$ \\
\hline $\mathrm{h}$ & $\begin{array}{l}\text { Favourite } \\
\text { sound }\end{array}$ & $\begin{array}{l}\text { Artistic: field } \\
\text { survey and } \\
\text { recording }\end{array}$ & $\begin{array}{l}\text { Favourite } \\
\text { sounds } \\
\text { database and } \\
\text { CD }\end{array}$ & {$[25]$} & $\mathrm{a}$ & $\begin{array}{l}\mathrm{a}, \mathrm{b}, \mathrm{c}, \\
\mathrm{i}, \mathrm{j}\end{array}$ \\
\hline $\mathrm{i}$ & $\begin{array}{l}\text { Exploration } \\
\text { of positive } \\
\text { soundscapes }\end{array}$ & $\begin{array}{l}\text { Artistic: } \\
\text { multiple } \\
\text { original } \\
\text { commissions }\end{array}$ & Art exhibition & {$[26]$} & All & f, g \\
\hline $\mathrm{j}$ & $\begin{array}{l}\text { Conceptual } \\
\text { framework }\end{array}$ & $\begin{array}{l}\text { Qualitative: } \\
\text { deskwork }\end{array}$ & $\begin{array}{l}\text { Sound-scape } \\
\text { perception } \\
\text { model }\end{array}$ & $\begin{array}{l}{[27, \text { this }} \\
\text { issue }]\end{array}$ & All & All \\
\hline $\mathrm{k}$ & $\begin{array}{l}\text { Soundscape } \\
\text { planning and } \\
\text { assessment }\end{array}$ & $\begin{array}{l}\text { Qualitative: } \\
\text { deskwork }\end{array}$ & $\begin{array}{l}\text { Methods for } \\
\text { planning and } \\
\text { assessment }\end{array}$ & [28] \& [29] & $\begin{array}{l}\mathrm{a}, \mathrm{b}, \\
\mathrm{c}, \mathrm{d}\end{array}$ & $\mathrm{i}, \mathrm{j}$ \\
\hline 1 & $\begin{array}{l}\text { Soundscape } \\
\text { expectation }\end{array}$ & $\begin{array}{l}\text { Qualitative: } \\
\text { interviews } \\
\text { and observed } \\
\text { simulator use }\end{array}$ & $\begin{array}{l}\text { Model of } \\
\text { expectation, } \\
\text { context and } \\
\text { competence }\end{array}$ & $\begin{array}{l}30] \\
\end{array}$ & $\mathrm{a}, \mathrm{g}$ & $\mathrm{i}, \mathrm{j}$ \\
\hline
\end{tabular}


Table 2. Core prompt script for the soundwalk interviews. These are the prompt questions used in the soundwalks. They were adapted slightly for the different participants (e.g. lay people vs. designers) and also extemporised as the immediate answers warranted.

\begin{tabular}{l|l}
\hline \multirow{2}{*}{ Initial pre- } & In general what do you expect to hear in an urban environment? \\
\cline { 2 - 2 } soundwalk & As an individual do you like or dislike these? \\
\hline \multirow{2}{*}{ At each specific } & What can you hear at the moment? \\
\cline { 2 - 2 } & What do you like most? Like least? Why? \\
\cline { 2 - 2 } & Does anything dominate? \\
\cline { 2 - 2 } & What do you think is in the background? \\
\cline { 2 - 2 } & Does this location sound as you would expect it to? \\
\cline { 2 - 2 } & How does this location make you feel? \\
\cline { 2 - 2 } & What aspects of the surroundings of this location do you think \\
\cline { 2 - 2 } & have an impact on the soundscape? \\
\cline { 2 - 2 } & Which of these aspects make the soundscape better/worse? \\
\cline { 2 - 2 } & How do you value this space? \\
\cline { 2 - 2 } & Who would you think uses this space? \\
\hline \multirow{2}{*}{ Foundwalk } & Would you say we have experienced a number of different \\
\hline
\end{tabular}




\begin{tabular}{l|l}
\hline \multirow{2}{*}{$\begin{array}{l}\text { soundscapes today or just one 'urban' soundscape? } \\
\text { them? }\end{array}$} & $\begin{array}{l}\text { If more than one, how would you classify the different types of } \\
\text { Has being on this soundwalk changed your perception or }\end{array}$ \\
\cline { 2 - 2 } & $\begin{array}{l}\text { Thinking of the different soundscapes you've experienced today } \\
\text { which ones work well? Why? }\end{array}$ \\
\cline { 2 - 2 } & What Manchester urban space do you prefer? Why? \\
\hline
\end{tabular}


Table 3. Core prompt script for the focus groups. These are the prompt questions used in the focus groups. They were adapted slightly for the different groups and also extemporised as the immediate discussion warranted.

\begin{tabular}{|c|c|}
\hline \multirow[t]{2}{*}{ Introductory } & $\begin{array}{l}\text { I'd like you to talk about your experiences when you are outdoors in an } \\
\text { urban setting. }\end{array}$ \\
\hline & $\begin{array}{l}\text { Can you tell me about the kind of things do you do; where you do } \\
\text { them; and in what way the time of day, week, year has an impact? }\end{array}$ \\
\hline \multirow[t]{3}{*}{ Transition } & $\begin{array}{l}\text { When you think about sound in the urban environment what do you } \\
\text { first think about? }\end{array}$ \\
\hline & What do you like about the sound of city centres? \\
\hline & $\begin{array}{l}\text { Summary: we've been talking about... could we now move on to } \\
\text { soundscapes. }\end{array}$ \\
\hline \multirow[t]{5}{*}{ Key } & What do you understand by the term 'soundscape'? \\
\hline & $\begin{array}{l}\text { If I said that a soundscape could be described as the 'sum of sounds' in } \\
\text { a space what do you think makes a positive soundscape and what } \\
\text { makes a negative soundscape? }\end{array}$ \\
\hline & $\begin{array}{l}\text { Say more about why you think these make the soundscape positive or } \\
\text { negative. }\end{array}$ \\
\hline & $\begin{array}{l}\text { How would you decide if sounds were wanted or unwanted in a } \\
\text { soundscape? }\end{array}$ \\
\hline & $\begin{array}{l}\text { In what ways, if any, do you think the soundscape influences people's } \\
\text { behaviour? }\end{array}$ \\
\hline
\end{tabular}




\begin{tabular}{l|l}
\hline \multirow{2}{*}{ soundscape? } & What factors do you think influence your perception of the \\
\cline { 2 - 2 } & $\begin{array}{l}\text { I'd like you to think about soundscapes more broadly now - in a } \\
\text { variety of settings, both rural and urban, and to talk about what you }\end{array}$ \\
\cline { 2 - 2 } & Hould value as a positive soundscape in those settings. \\
\cline { 2 - 2 } & If you had the opportunity to create a positive soundscape what would \\
& it be?
\end{tabular}


Figure 1. Route of the Manchester sound walk.

Figure 2. The main soundscape components revealed in the analysis of the soundwalk interviews. 


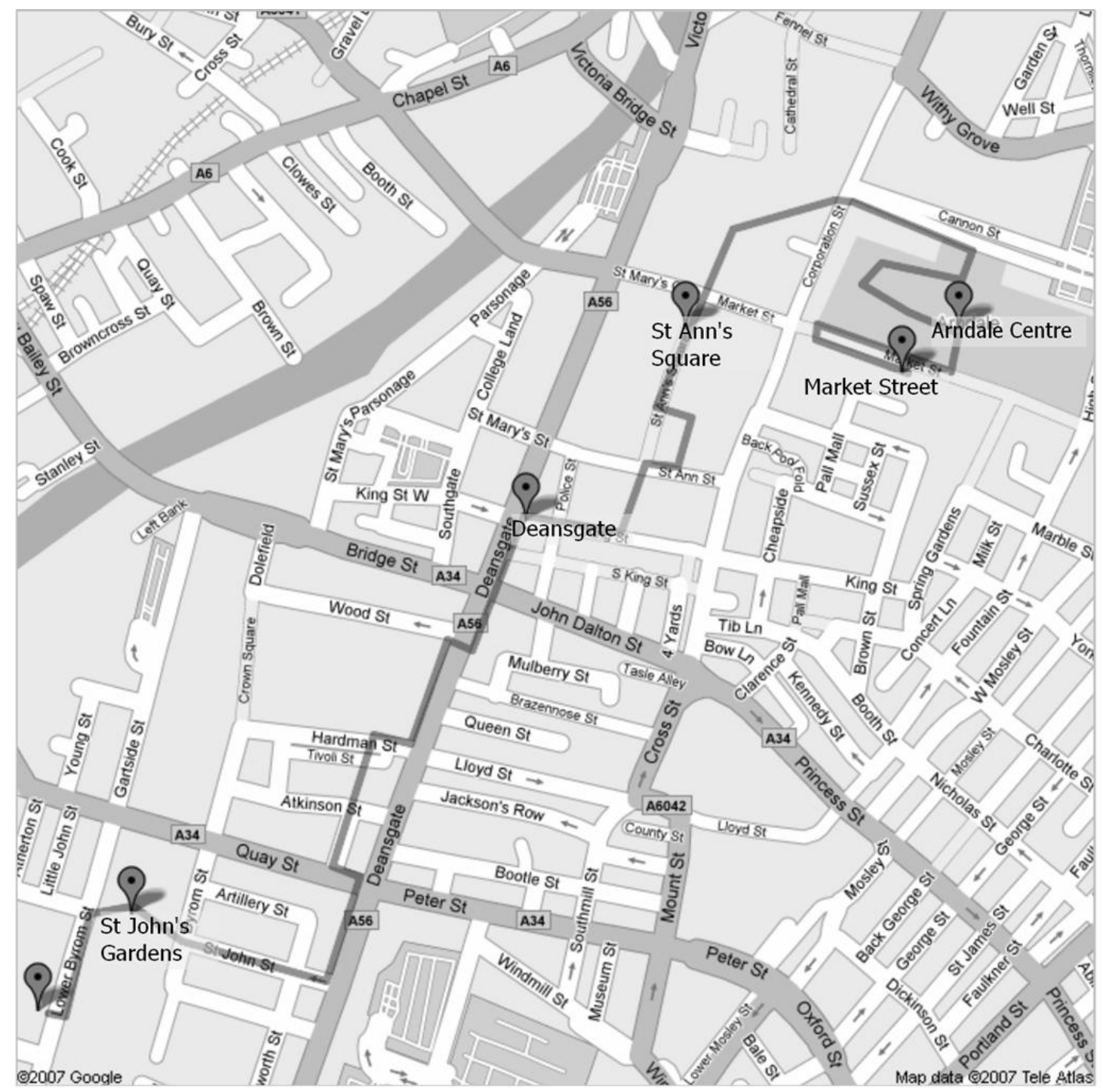




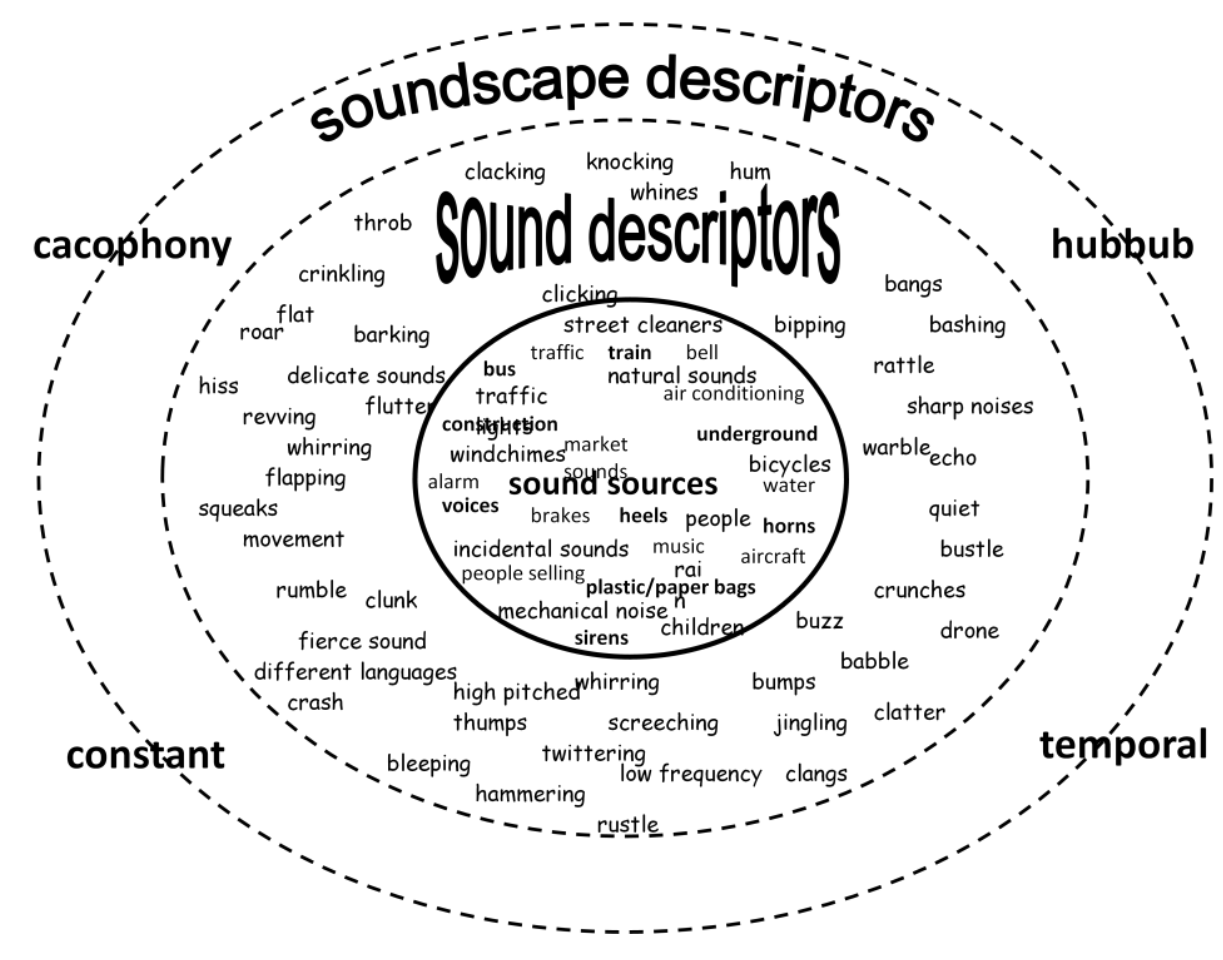

